\title{
Impact of Stress Factors on Part-Time College Students
}

\author{
Gudrun Gaedke Barbara Covarrubias Venegas Philipp Simbrunner \\ FHWien University of Applied Sciences, Institute for Human Resources and \\ Knowledge Management, Vienna, Austria \\ Gerald Janous \\ FHWien University of Applied Sciences, Institute for Marketing and \\ Sales Management, Vienna, Austria
}

\begin{abstract}
This paper presents and discusses intermediate results of a longitudinal study on stress and exhaustion in part-time college students. Study, in addition to full-time or part-time employment, gives students a triple burden consisting of work, study and leisure or family. This stress situation often leads to dropouts or leaves of absence or even health effects on students. The purpose of this study is to identify the factors that can affect academic success systemically over the curriculum, in order to incorporate preventive measurements in teaching as well as in the central university organization from an early stage.
\end{abstract}

\section{Introduction}

Austrian universities of applied sciences currently offer (in the academic year 2010/11) over 120 courses in part-time form [2]. This part-time version of study implies for students, in many cases, a triple burden: they must balance work, study and private or family life [3]. The effects of this stress situation show in students, who interrupt studying, do not finish the course (drop out) or suffer from health impairment [4]. Previous studies [3, 4] mostly concern the living conditions of students and relate mainly to students at universities; they cover only parts of this problem. In particular, referring to parttime students at universities of applied sciences, there is no comprehensive empirical insight. Existing studies do not allow drawing a clear picture of the triple burden situation of these students.

Since the proportion of full-time or part-time students will increase with regards to the increasing implementation of Master programs in the future, the need for systematic knowledge about the burden situation of this group of students rises as well. Only the creation of a new information base allows identifying the factors that affect academic success and enables universities of applied sciences to establish prevention measures from an early stage on. The aim is to prevent the drop out of students, and accordingly, to increase the rate of students who successfully graduate.

The aim of the present study is to capture the subjective burden of part-time students of the FHWien courses of the WKW over time in all aspects. In a three-year qualitative and quantitative longitudinal study, the students have been regularly surveyed about their stressful situations with regards to their studies or organizational aspects of their studies, as well as to their work and private life. From the results of this study, measures have been developed regarding the lectures as well as the central university organization. The implementation of these measures has been evaluated in the later surveys.

\section{Empirical study}

In this paper the focus is given to analyse structures of conditions, which may explain the student's perceived stress level. As a second aspect potentially stress-lowering measures have been determined.

\subsection{Method}

The study has been conducted by the Institute of Personnel and Knowledge Management and the Institute for Marketing and Sales Management, FHWien courses of WKW, during the period from 2009 to 2011. Students of Bachelor and Master degree programs in the FHWien courses of WKW, both actively employed and full-time students, have been polled in order to additionally conduct a systematic comparison of their experiences.

The analysis of an entire bachelor's degree program consisting of six semesters is only possible for the academic year 2008/09, which ends in 2011. The master's programs could not be considered due to the small number of students in the programs.

A total of 2,033 students took part in the survey, of which 1,071 study part-time and 962 full-time.

The gender distribution of participants in both forms of study corresponds to the global gender distribution of $60 \%$ women and $40 \%$ of men at the 
FHWien University of Applied Sciences degree programs of WKW.

The response rates of all respondents varied from $23 \%$ to $36 \%$; with consistently more than $20 \%$ for an online survey, they can be classified as very good.

The focus of the survey was on the workload of each past semester. For this purpose, a questionnaire was developed which surveys the subjective strain of students. The questionnaire consists of items concerning the burden of study, profession and private/family life.

Another aspect which the study considers is the exposure of students due to particular courses of the semester. Therefore, the burden of attending the course, the burden of examinations and the burden of additional work for the course are separately evaluated.

In addition, students are asked about measures which they take to enable them to cope better with stress from the course of study. The questionnaire ends with an open question which allows students to propose organizational measures on the part of the college organization that may reduce the perceived stress situation.

The survey has been using an online questionnaire carried out for each existing preceding semester. Thus, data are available from the winter term 2008, 2009 and 2010 and from the summer term 2009 and 2010.

The collected data were analyzed using SPSS uniand multivariate analysis.

In addition to the online survey, the subjective stress experience in extreme situations was examined by qualitative interviews with students and graduates who suffered burnout. For that, a semi-structured interview guide was developed and adapted for a pretest phase. A total of 13 interviews were conducted. Results of the qualitative data were used to create a guide to handle stressful situations during the study-time [5].

\subsection{Multiple regression analyses}

To identify structures of conditions, which may explain the student's perceived stress level, stepwise multiple regression analyses were conducted. These were carried out separately for the five surveys and the groups of fulltime and part-time students, yielding a total of ten analyses. In the results section, regression coefficients (b and beta values) are reported for the model, which explains the greatest amount of variance (adjusted $\mathrm{R}^{2}$ ). B-values indicate the amount of change in the criterion variable, if the corresponding predictor variable is changed by one unit. The beta-value shows a corresponding predictor variable's influence on the criterion variable, it has, if regarded with the other predictors simultaneously. Regression coefficients, like correlation coefficients, allow no causal interpretation, and our principal goal was not to find any such causally interpretable results.

The aim of these analyses was to find combinations of (observable) factors, which are related to student's perceived stress level. Perceived stress caused by studying was the criterion-variable.

The following items were entered into the model as predictor variables. All items were rated on a Likert-scale, ranging from 1 (not at all burdened) to 10 (very burdened): a) perceived stress caused by studying - this item was the criterion, all the other variables were used as predictors, b) perceived stress on workplace, c) perceived stress caused by private life, d) use of some way of cooperation with other students, e) use of time management skills, f) reduction of aspiration level, g) reduction of social activities and h) reduction of occupational commitment.

Another aspect of the present analysis was to determine potentially stress-lowering measures.

Students were asked to propose organizational measures on the part of the college organization that may reduce the perceived stress situation. This open question was only included in the first two administrations of the survey.

The frequencies of mentioned categories are presented in the results section separately for the two surveys and the groups of fulltime and part-time students. These suggestions were all read and assigned to one of the following categories: a) Timetable: distribution of classes and exams, having a voice in making up the timetable (i.e. blocking, at least one free day per week, classes during weekends etc.) etc. b) Curriculum: adaption of and coordination between classes as regards content, cancellation of "useless" classes etc. c) Additional tasks outside classes: reduction of projects, homework and presentations, big projects instead of many smaller ones d) Didactics: use of blended and/or e-Learning, more qualified teachers, better teaching material, (accurately timed) etc. e) Compulsory attendance: cancellation, easing etc. f) Department-specific: accurately timed notification about (changes in) appointments, better communication with students in general, more flexibility, better organization etc. g) University in general: cheap cafeteria, quiet workplaces on campus, extended library opening hours etc.

Additionally, we conducted several bivariate correlational analyses. Most of the hereby gained findings are included in the multiple regression analyses and are therefore not being reported separately. Noteworthy additional findings are presented in the results section.

\section{Results}

In the following, some selected results of the study are presented. The denoted values arise from 
the percentage means of all conducted studies, unless otherwise specified.

\subsection{General stress situation comparing part- time / full-time on selected factors}

The overall mean of the perceived burden by students due to studying, measured on a scale from " 1 = not at all burdened" to "10 = very heavy burdened”, is 7.10 for part-time and full-time students (summer term 2010).

Part-time students felt slightly more burdened by studying (average of 7.24 in summer term 2010) (6.96) than did full-time students.

Female students and male students did not differ significantly in terms of the subjective impact of the study.

The perceived stress caused by work for part-time students increased with studying (the mean of the exposure through the profession on a scale from " 1 = not at all burdened" to " 10 = very heavy burdened" before the study was 5.46 and after the beginning of the study was 6.37).

The perceived impact of private life for part-time students increased significantly with entry into the study programs (the mean of the burden due to private life on a scale from " 1 = not burdened at all" to " 10 = very heavy burdened" rose from 3.41 before the study to 5.22 after the start of the study).

\subsection{Extent of employment comparing part- time / full-time students}

More than $74.8 \%$ of part-time students worked 40 hours or more per week, of which approximately $30.6 \%$ worked 40-50 hours per week.

The proportion of part-time students working up to 20 hours per week was low $(10 \%)$.

About $30 \%$ of the full-time students were not working.

More than half of the full-time students (about $59.2 \%$ ) worked up to 10 hours $(39.7 \%)$ or up to 20 hours (19.4\%) per week.

\subsection{Handling of the study load}

The survey participants were asked about their personal handling of burden imposed on them by the study during the semester. To this end, students had to rate the following statements on a scale from " $1=$ applies not at all” to " $10=$ I agree very strongly":

Most striking is the result in terms of the reduction of private activities, indicating that the part-time students reduce their private activities to a large extent (the average is 7.91). This result was confirmed in the survey.

\subsection{Results of the regression analyses}

The results of the regression analyses are presented in table 1 for fulltime students (ft) and for part-time students (pt), separately for all five surveys (t1 to t5). Predictors in the models are sorted in descending order regarding their specific contribution to explaining the variance in student's perceived stress levels (beta-values). Variables not included in table 1 did not meet criterion for inclusion $(\mathrm{p}<.05)$ or exclusion $(\mathrm{p}<.10)$. In text, betavalues are reported along with the corresponding $b$ values, means and standard deviations.

\section{Table 1. Regression model summaries}

\begin{tabular}{|c|c|c|c|}
\hline & & Predictors & $\operatorname{adj} . R^{2}$ \\
\hline \multirow[b]{2}{*}{ t1 } & $\mathrm{ft}$ & $\begin{array}{l}\text { social activities, occupational } \\
\text { commitment, aspiration level }\end{array}$ & 0,39 \\
\hline & pt & $\begin{array}{lrr}\begin{array}{l}\text { stress on } \\
\text { activities, }\end{array} & \begin{array}{r}\text { workplace, } \\
\text { private } \\
\text { occupational } \\
\text { aspiration level }\end{array} & \begin{array}{r}\text { sommitment, } \\
\text { life, }\end{array} \\
\end{array}$ & 0,31 \\
\hline \multirow{2}{*}{ t2 } & $\mathrm{ft}$ & $\begin{array}{l}\text { social activities, cooperation } \\
\text { with others }\end{array}$ & 0,23 \\
\hline & pt & $\begin{array}{l}\text { stress on workplace, social } \\
\text { activities }\end{array}$ & 0,23 \\
\hline \multirow[b]{2}{*}{ t3 } & $\mathrm{ft}$ & social activities & 0,20 \\
\hline & pt & $\begin{array}{l}\text { social activities, } \\
\text { workplace, } \\
\text { commitment }\end{array}$ & 0,36 \\
\hline \multirow[b]{2}{*}{ t4 } & $\mathrm{ft}$ & social activities & 0,13 \\
\hline & pt & $\begin{array}{l}\text { social activities, stress on } \\
\text { workplace, } \\
\text { commitment }\end{array}$ & 0,20 \\
\hline \multirow[b]{2}{*}{ t5 } & $\mathrm{ft}$ & social activities, private life & 0,42 \\
\hline & $\mathrm{pt}$ & $\begin{array}{l}\text { social activities, aspiration level, } \\
\text { stress on workplace }\end{array}$ & 0,15 \\
\hline
\end{tabular}

In table 2 descriptive statistics for the criterion variable, perceived stress caused by studying, are presented. The sample size $(\mathrm{N})$ column in table 2 refers to all variables reported for the specific survey and study group.

Table 2. Descriptive statistics for perceived stress caused by studying

\begin{tabular}{|l|l|l|l|l|l|l|}
\hline & \multicolumn{3}{|l|}{ fulltime } & \multicolumn{2}{l|}{ part-time } \\
\hline & $\mathrm{N}$ & $\mathrm{M}$ & $\mathrm{SD}$ & $\mathrm{N}$ & $\mathrm{M}$ & $\mathrm{SD}$ \\
\hline t1 & 280 & 6,23 & 2,01 & 288 & 7,1 & 1,78 \\
\hline t2 & 183 & 6,89 & 1,92 & 209 & 7,2 & 1,7 \\
\hline t3 & 243 & 6,96 & 1,78 & 268 & 7,24 & 1,8 \\
\hline t4 & 165 & 6,85 & 1,79 & 240 & 7,53 & 1,61 \\
\hline t5 & 163 & 6,59 & 1,88 & 250 & 7,2 & 1,85 \\
\hline
\end{tabular}




\subsection{Stress factors - fulltime students}

In the first survey (t1) the reduction of social activities was the most important variable with a beta-value of $.51(\mathrm{~b}=.32, \mathrm{M}=5.83, \mathrm{SD}=3.17)$. Reduction of occupational commitment and reduction of one's aspiration level showed a betavalue of $.20(\mathrm{~b}=.11, \mathrm{M}=5.04, \mathrm{SD}=3.65)$ and of $.10(\mathrm{~b}=.07, \mathrm{M}=4.39, \mathrm{SD}=2.95)$ respectively. The constant for the regression model equation was 3.49.

The reduction of social activities was also the most important variable in the second survey $(\mathrm{t} 2)$ with a beta-value of $.47(\mathrm{~b}=.29, \mathrm{M}=6.37, \mathrm{SD}=$ 3.09). The amount of cooperation with others was the second variable in the model, showing a betavalue of $.14(\mathrm{~b}=.09, \mathrm{M}=5.67, \mathrm{SD}=2.87)$. The equation's constant was 4.50 .

In the third (t3) and fourth (t4) survey the reduction of social activities was the only variable in the models with beta-values of $.45(\mathrm{~b}=.27, \mathrm{M}=$ $6.57, \mathrm{SD}=2.97)$ and $.36(\mathrm{~b}=.21, \mathrm{M}=5.96, \mathrm{SD}=$ $3.10)$ respectively. The constant showed a value of 5.18 in $\mathrm{t} 3$ and of 5.60 in $\mathrm{t} 4$.

In the fifth survey (t5) the reduction of social activities was again the variable with the highest beta-value of .53 ( $\mathrm{b}=.34, \mathrm{M}=6.25, \mathrm{SD}=2.95$ ). Stress caused by private life was the second component in the model (beta $=.27, \mathrm{~b}=.22, \mathrm{M}=$ $5.10, \mathrm{SD}=2.28$ ). The constant term was 3.35 .

\subsection{Stress factors - fart-time students}

In $\mathrm{t} 1$ perceived stress on workplace was the most important variable with a beta-value of $.32(b=.29$, $M=6.62, S D=2.05$ ). Reduction of social activities was the second most important variable with a betavalue of $.22(\mathrm{~b}=.17, \mathrm{M}=8.20, \mathrm{SD}=2.25)$. Other variables in this model were stress caused by private life (beta $=.16, \mathrm{~b}=.11, \mathrm{M}=4.80, \mathrm{SD}=2.46$ ), reduction of occupational commitment (beta $=.16$, $\mathrm{b}$ $=.09, \mathrm{M}=4.59, \mathrm{SD}=3.20)$ and reduction of one's aspiration level (beta $=.13, \mathrm{~b}=.07, \mathrm{M}=4.82$, $\mathrm{SD}=$ $3.21)$. The constant for the regression model equation was 2.54 .

In $\mathrm{t} 2$ perceived stress on workplace and reduction of social activities were the only variables included in the model. They showed beta-values of $.37 \mathrm{(b}=$ $.32, \mathrm{M}=6.53, \mathrm{SD}=2.01)$ and of $.30(\mathrm{~b}=.23, \mathrm{M}=$ $8.17, \mathrm{SD}=2.22$ ) respectively. The equation's constant was 3.27 .

In $\mathrm{t} 3$ and $\mathrm{t} 4 \mathrm{the}$ reduction of social activities, perceived stress on workplace and the reduction of occupational commitment were represented in the models. Reduction of social activities showed betavalues of $.38(\mathrm{~b}=.28, \mathrm{M}=7.91, \mathrm{SD}=2.51)$ in $\mathrm{t} 3$ and $.32(\mathrm{~b}=.21, \mathrm{M}=8.01, \mathrm{SD}=2.38)$ in $\mathrm{t} 4$. The betavalues for perceived stress on workplace were .34 (b $=.28, \mathrm{M}=6.37, \mathrm{SD}=2.14)$ in $\mathrm{t} 3$ and $.32(\mathrm{~b}=.17, \mathrm{M}$ $=6.40, \mathrm{SD}=2.20)$ in $\mathrm{t} 4$. The values for the reduction of occupational commitment in the two surveys were $.18(\mathrm{~b}=.11, \mathrm{M}=4.22, \mathrm{SD}=2.99)$ and $.14(\mathrm{~b}=.07$, $\mathrm{M}=4.47, \mathrm{SD}=3.12$ ) respectively. The constant's value was 2.79 in $\mathrm{t} 3$ and 4.40 in $\mathrm{t} 4$.

In 5 reduction of social activities was the most important variable in the model with a beta-value of $.27(\mathrm{~b}=.19, \mathrm{M}=7.90, \mathrm{SD}=2.60)$. The reduction of one's aspiration level showed a beta-value of .16 (b $=.09, \mathrm{M}=5.44, \mathrm{SD}=3.27$ ). Perceived stress on workplace was the third variable in this model with a beta-value of $.14(\mathrm{~b}=.13, \mathrm{M}=6.42, \mathrm{SD}=1.98)$. The constant term was 4.35 .

\subsection{Stress lowering measures}

In table3, the frequencies of mentioned measures are reported. For fulltime students, the timetablecategory is by far the most important. Almost half of all the collected suggestions fall within this category. Additionally, only changes concerning departmentspecific characteristics are represented with more than ten percent of all mentioned measures. For parttime students, there are three categories accounting for more than ten percent of all suggestions in both surveys. These are the categories timetable, department-specific and didactics. Changes concerning additional tasks outside classes and accordingly concerning compulsory attendance were important categories for over ten percent of all parttime students in $\mathrm{t} 1$ and $\mathrm{t} 2$ respectively.

Table 3. Mentioned measures by student group and survey

\begin{tabular}{|c|c|c|c|c|}
\hline & \multicolumn{4}{|c|}{ group and surve } \\
\hline & \multicolumn{2}{|c|}{$\mathrm{t} 1$} & \multicolumn{2}{|c|}{ t2 } \\
\hline & pt & $\mathrm{ft}$ & pt & $\mathrm{ft}$ \\
\hline Timetable & $\begin{array}{c}27,0 \% \\
77\end{array}$ & $45,3 \%$ & $36,8 \%$ & $\begin{array}{c}44,9 \% \\
75\end{array}$ \\
\hline $\begin{array}{l}\text { Department- } \\
\text { specific }\end{array}$ & $\begin{array}{c}23,5 \% \\
67\end{array}$ & $\begin{array}{c}23,5 \% \\
58\end{array}$ & $\begin{array}{c}16,5 \% \\
30\end{array}$ & $\begin{array}{c}21,0 \% \\
35\end{array}$ \\
\hline $\begin{array}{l}\text { Additional } \\
\text { tasks outside } \\
\text { classes }\end{array}$ & $\begin{array}{c}18,6 \% \\
53\end{array}$ & $\begin{array}{c}4,9 \% \\
12\end{array}$ & $\begin{array}{c}8,2 \% \\
15\end{array}$ & $\begin{array}{c}4,2 \% \\
7\end{array}$ \\
\hline Didactics & $\begin{array}{c}14,4 \% \\
41\end{array}$ & $\begin{array}{c}9,7 \% \\
24\end{array}$ & $\begin{array}{c}19,2 \% \\
35\end{array}$ & $\begin{array}{c}9,0 \% \\
15\end{array}$ \\
\hline $\begin{array}{l}\text { Compulsory } \\
\text { attendance }\end{array}$ & $\begin{array}{c}9,1 \% \\
26\end{array}$ & $\begin{array}{c}4,0 \% \\
10\end{array}$ & $\begin{array}{c}11,0 \% \\
20\end{array}$ & $\begin{array}{c}9,0 \% \\
15\end{array}$ \\
\hline $\begin{array}{l}\text { University in } \\
\text { general }\end{array}$ & $\begin{array}{c}4,9 \% \\
14\end{array}$ & $\begin{array}{c}7,3 \% \\
18\end{array}$ & $\begin{array}{c}2,2 \% \\
4\end{array}$ & $\begin{array}{c}6,0 \% \\
10\end{array}$ \\
\hline Curriculum & $\begin{array}{c}2,5 \% \\
7\end{array}$ & $\begin{array}{c}5,3 \% \\
13\end{array}$ & $\begin{array}{c}6,0 \% \\
11\end{array}$ & $\begin{array}{c}6,0 \% \\
10\end{array}$ \\
\hline$N$ & 285 & 247 & 182 & 167 \\
\hline
\end{tabular}

\subsection{Time management}

Additionally, several bivariate correlation analyses were conducted. Most of these results reflect the findings from the multiple regression analyses and therefore only results offering new information are being presented here. Spearman rank 
correlations showed significant correlation between the use of time management skills and the handling of compulsory attendance. The handling of compulsory attendance was rated on a three-point scale, with $1=\mathrm{I}$ try attend classes as often as possible; 2 = I plan my non-attendance within the 25-percent-rule; and 3 = I risk falling below the 75percent-mark (note: students are obliged to attend classes and will face consequences if they failed to attend at least 75 percent of classes). This variable was not included in the first survey. The correlation coefficients for fulltime students were $\mathrm{r}=-.2(\mathrm{n}=$ 183, $\mathrm{p}<0.01)$ in $\mathrm{t} 2, \mathrm{r}=-.22(\mathrm{n}=243, \mathrm{p}<0.01)$ in $\mathrm{t} 3$, $\mathrm{r}=-.32(\mathrm{n}=165, \mathrm{p}<0.01)$ in $\mathrm{t} 4$ and $\mathrm{r}=-.23(\mathrm{n}=$ $136, \mathrm{p}<0.01)$ in t5. For part-time students the results were $\mathrm{r}=-.19(\mathrm{n}=209, \mathrm{p}<0.01)$ in $\mathrm{t} 2, \mathrm{r}=-.21(\mathrm{n}=$ 268, $\mathrm{p}<0.01)$ in $\mathrm{t} 3, \mathrm{r}=-.26(\mathrm{n}=240, \mathrm{p}<0.01)$ in $\mathrm{t} 4$ and $\mathrm{r}=-.17(\mathrm{n}=250, \mathrm{p}<0, .1)$ in $\mathrm{t} 5$.

Pearson correlation between the use of time management skills and the reduction of one's aspiration level were conducted. The correlation coefficients for fulltime students were $\mathrm{r}=-.21 \mathrm{(n}=$ 289, $\mathrm{p}<0.01)$ in $\mathrm{t} 1, \mathrm{r}=-.21(\mathrm{n}=183, \mathrm{p}<0.01)$ in $\mathrm{t} 2$, $\mathrm{r}=-.15(\mathrm{n}=243, \mathrm{p}<0.05)$ in $\mathrm{t} 3, \mathrm{r}=-.26(\mathrm{n}=165, \mathrm{p}$ $<0.01)$ in $\mathrm{t} 4$ and $\mathrm{r}=-.21(\mathrm{n}=163, \mathrm{p}<0.01)$ in $\mathrm{t} 5$. For part-time students the results were $\mathrm{r}=-.22(\mathrm{n}=$ 288, $\mathrm{p}<0.01)$ in $\mathrm{t} 1, \mathrm{r}=-.22(\mathrm{n}=209, \mathrm{p}<0.01)$ in $\mathrm{t} 2$, $\mathrm{r}=-.31(\mathrm{n}=268, \mathrm{p}<0.01)$ in $\mathrm{t} 3$ and $\mathrm{r}=-.21(\mathrm{n}=$ $240, \mathrm{p}<0.01)$ in $\mathrm{t} 4$. In $\mathrm{t} 5$ the correlation was -0.06 $(n=250)$ but did not fall below the significance level of $<.05$.

\section{Discussion}

In this section the main findings of this study are being discussed. Practical implications of our analyses' results are emphasized in particular. Additionally, future research directions are being proposed.

\subsection{General findings}

With the present results of the study, empiricallybased insights on the level of stress and exhaustion in students are delivered. As already presumed, it was found that the burden of study has a higher impact on part-time students than on full-time students. The burden of part-time students is higher overall, since with the beginning of the study, the subjectively-felt burden due to the job as well as to private life increases. Any additional burden such as child care or budget management also adds to the perceived exhaustion of part-time students.

The results provide useful data for teaching as well as for the central university organization. In particular, the curriculum and the curriculum design should consider factors which were identified as a burden, in order to avoid stress concentrations. Study results concentrating on rating every single course of the different study programs offered by the FHWien courses of the WKW may be used for this cause as well. For all courses (and accordingly, the central areas of the FHWien courses of WKW) tangible measures could be derived without the loss of quality of the curriculum or the services offered. These measures concern, for example, the distribution of courses and exams as well as additional tasks in the curriculum throughout the semester. Furthermore, the issue was taken up by students in stressful situations who sought discussions with lecturers in order to raise awareness of the specific exposure, in particular the part-time students [6].

\subsection{Indicators of student's stress levels}

Regression coefficients, like correlation coefficients, are not to be interpreted causally, because one does not know which factor really influences the other. For instance, it is not known if perceived stress causes reduction of social activities or vice versa. However, we believe that both directions are not only possible, but given. We see student's perceived stress levels in a dynamic environment, influenced by the analyzed factors and influencing these factors in turn. From this point of view, our results can be taken as if they were causally interpretable. Within this framework, the predictor variables can be seen as indicators of student's stress levels. These indicators are better observable and therefore open the possibility to identify students, who are burdened with stress.

Reduction of social activities occurred in all surveys and all student groups as an important stresselevating factor. This finding is supported by Jacob and Dodd (2003) [7], who showed in their study, that social support from friends has a reducing effect on student's burn out risk. Perceived stress on workplace is an important factor within the group of part-time students and occurred in all surveys.

All other variables were not represented systematically over time and groups. Three times the reduction of occupational commitment was contained in regression models for part-time students. Even though this variable was not represented systematically, our results show evidence and support for the conclusion that this factor plays an important role in part-time students' stress levels. All other analyzed variables were not represented systematically. If these factors are important in explaining perceived stress levels, or if the here gained results were by chance, is a question to be followed in future research.

Overall, our results show that conditional structures explaining perceived stress levels among part-time students are more complex than among fulltime students. Regression models for the former group consisted of three to five different variables 
each, whereas those for the latter compromised between one and three different factors each.

The importance of perceived stress at work supports the assumption, that university and workplace form two sources of stress. In our surveys we did not explore workplace-related conditions, which influence perceived stress levels at work. Further research in this direction is needed.

Interestingly, concerning the assumed third source of stress, which was private life, no systematically occurring link to the other two sources could have been found.

\subsection{Practical implications for students}

The first practical implication of our findings is to advise all students not to reduce their social activities. When they experience high stress levels caused by their study, they are encouraged not to drop extracurricular and non-occupational activities, like sports or social commitment. Not dropping any such activities seems counterintuitive in particular to part-time students, but these are sources of interaction with others. Reducing such activities leads to greater social isolation, which is counterproductive in handling stressful phases in life.

Factors causing stress at work were not examined, but instability in general can be seen as a potential source of stress. Instability can be caused by many circumstances like job losses, job changes or even by job promotions. Applicants for places in part-time programs are advised to ensure a stable occupational environment as far as possible for the study program's duration. Students already enrolled in part-time programs are advised not to change their current jobs or aspire to promotions until their graduation.

\subsection{Supporting Measures}

The analysis of students' desired measures showed a variety of different opportunities which can be realized to reduce perceived stress levels among students. Approximately two third of all mentioned desired measures by fulltime students fell within only two categories. Part-time students' needs showed more diversity, but the two most important categories were the same as for the other student group.

\subsection{Practical implications for the university}

In this section, mentioned measures are being presented. These suggestions can be employed directly.

The timetable-category was the most important one and the following changes fall within it: Timetables should be planned in a way, that there is (at least) one day per week without classes. Ideally, classes are held on consecutive days, for instance from Monday to Thursday and not from Monday to Friday with a free Wednesday in between. There should not be large gaps between two classes held on the same day. Classes should not be held on weekends, unless a course is blocked, for instance two week-ends per semester instead of being distributed over the whole semester and held once a week. Additionally, exams should not be taken mostly in a term's last week(s) but rather be distributed more or less equally. Finally, having a say in the creation of timetables is wished.

Department-specific measures were the secondmost important category, which compromises the following: The communication between departments and students is an important factor. E-Mails, phone calls etc. should be answered promptly and accurately. Notifications concerning changes in appointments, for instance cancellations of classes, should be made several days in advance.

Additional tasks, which have to be done outside classes, are project works, preparing presentations and different homework tasks. Few but big projects are preferred instead of many but small ones. The amount of additional tasks in general should not be too big.

Desired measures concerning didactics were as follows: The use of different forms of distance learning and e-Learning should be extended. Students desire the allocation of study materials by teachers and wish to have access to these materials via e-Learning platforms. Materials should be up to date.

Students are obliged to attend classes and will face consequences if they fail to attend 75 percent of one course. The cancellation of the compulsory attendance for at least some courses is desired, by way of example for courses dealing with basics of a given topic, which could be learned easily at home. Easing the 75-percent-rule is wished as well, but not possible, because of compulsory law.

\subsection{Time Management}

Additional analyses showed a correlation between the use of time management skills the both the handling of compulsory attendance and the reduction of one's aspiration level. Obviously, having the ability to manage one's own time budget, helps in handling attendance. Good time management skills might lead to more realistic expectations regarding one's own future achievement and thus helps in developing and maintaining a realistic aspiration level.

From a university's perspective, it is wished that students attend classes and keep their aspiration levels. Our results support the assumption, that time management skills are important in this context. The 
practical implication of this finding is, that this soft skill should be taught and trained.

\section{Conclusion}

The results provide new empirical evidence on the level of exhaustion and stress in part-time students during the course of their studies at universities of applied sciences. The results allow conclusions for the teaching environment and the central organization of institutes of higher education, from which specific measures at the individual level of the students can be derived.

Special attention should be paid to sensitizing affected students themselves, fellow students, teachers and staff of the university as well as prospective students and applicants to this subject, so that action can be taken in an early stage. The central organization of institutes of higher education should therefore focus on information and provision of support activities.

A major part of burnout prevention is education and awareness about burnout in students. Awareness should be raised from the beginning of the study pursuits. In the future, screenings and a self-test should be made available for students before they start studying to enable them to reflect on their decision and assess their current situation. This may induce a process of self-reflection and leave students room to take measures before the studies start.

In addition, universities should evaluate the level of stress which is experienced by the students on a regular basis. This not only provides awareness of exhausting situations but also enables universities to take measures (e.g. a different schedule distribution as was done by the FH Wien).

Since the presented study is a long-term study, it will be possible to derive the potential exposure situations throughout the course of the study of a bachelor's degree at the end of the survey in 2011. The next step will be to investigate whether the results can be generalized due to the organization of the study, or if age group effects are crucial for the results.

\section{Acknowledgements}

This project is part of the 9th Invitation of the Vienna University School-Funding Program in 2005 by the City of Vienna, Municipal Department 27, with EU-strategy and business development support.

\section{References}

[1] This study was presented at the Ireland International Conference on Education in Dublin (IICE 2011), October $3^{\text {rd }}$ to $5^{\text {th }} 2011$. This publication is an extended version of the presented paper.

[2] FHR (FH-Council) (2011) Aktuelle Statistische Auswertungen, www.fhr.ac.at (15 April 2011).

[3] Schlögl, P. and Neubauer, P. (2006) Vereinbarkeit von Studium und Berufstätigkeit in ausgewählten Universitätsund Fachhochschul-Studienrichtungen in Wien, öibf Österreichisches Institut für Bildungsforschung, Vienna.

[4] Unger, M. and Wroblewski, A. (2006) StudierendenSozialerhebung 2006. Bericht zur sozialen Lage der Studierenden, IHS Projektbericht, Vienna.

[5] FHWien (FHWien Studiengänge der WKW) (2011) ,Arbeiten und Studieren: Leitfaden zum Management von Belastungssituationen', Vienna.

[6] Gaedke, G., B. Covarrubias Venegas, S. Recker and G. Janous (2011) 'Vereinbarkeit von Arbeiten und Studieren bei berufsbegleitend Studierenden', Zeitschrift für Hochschulentwicklung, ZFHE Jg. 6/Nr. 2 (June 2011), pp. $198-213$.

[7] Jacobs, S. R. and Dodd, D. K. (2003) 'Student Burnout as a Function of Personality, Social Support and Workload', Journal of College Student Development, 44, pp. 291-303. 